\title{
Compras públicas como política para o desenvolvimento sustentável
}

\author{
Bernardo Carlos S. C. M. de Oliveira \\ Pontifícia Universidade Católica de São Paulo (PUC-SP) \\ Luis Miguel Luzio dos Santos \\ Universidade Estadual de Londrina (UEL-PR)
}

\begin{abstract}
Este estudo propõe-se a compreender como o Estado tem contribuído para o desenvolvimento sustentável a partir de seu poder de compra, mais precisamente, ao se comparar práticas e regulamentações no estado de São Paulo e os da região Sul. Quanto ao método de pesquisa, foi utilizada a pesquisa bibliográfica e documental, em editais e legislações dos estados supracitados, compreendendo os anos de 2011 a 2013. Verificou-se que os avanços se limitam a questões ambientais e à dimensão social. Avanços, embora tímidos, fortalecem modelos organizacionais não centrados na maximização do lucro, voltados à inclusão social, à justiça distributiva, ao equilíbrio ambiental e ao bem viver coletivo, prerrogativas dos empreendimentos de economia solidária, empresas sociais e cooperativas populares, que podem ser particularmente alavancadas.
\end{abstract}

Palavras-chave: compras públicas; compras públicas sustentáveis; questão socioambiental.

\section{Contratación pública como política para el desarrollo sostenible}

El presente estudio trata de comprender cómo el Estado ha contribuido con el desarrollo sostenible mediante su poder de compra, más precisamente, al comparar las prácticas y regulaciones en los estados brasileños de Sao Paulo y el sur. En cuanto al método de investigación, la literatura y documentos, se utilizaron las leyes y decretos en los estados antes mencionados, que comprende los años 2011 a 2013. Se constató que los adelantos están limitados a cuestiones ambientales y la dimensión social sin privilegios. Los avances, aunque tímidos, fortalecen los modelos de organización que no se centran en la maximización del beneficio, dirigido a la inclusión social, la justicia distributiva, equilibrio ambiental y la buena vida colectiva, que son la prerrogativa de las empresas de economía solidaria, empresas sociales y cooperativas populares, que pueden ser aprovechadas en particular.

Palabras clave: compras públicas; compras públicas sostenibles; cuestión social y ambiental.

DOI: http://dx.doi.org/10.1590/0034-76121833

(cc) BY-NC

Artigo recebido em 21 jan. 2014 e aceito em 9 set. 2014. 
Public procurement as a policy for sustainable development

This study aims to understand how the State has contributed to sustainable development through their purchasing power, more precisely, when comparing practices and regulations in the Brazilian states of São Paulo and the ones of the South region. Regarding the method of research, bibliographical and documental research was conducted in the legislation and notices of the above states, through the years 2011-2013. It was found that the advancements are limited to environmental issues and social dimension. Advances, although in a soft way, strengthen the organizational models which are not focused on profit maximization, turned to social inclusion, distributive justice, environmental balance and well-being of the community, which are basic prerogatives of the solidarity economy, social enterprises and popular cooperatives, which may be particularly leveraged.

KEYWORDs: public procurement; sustainable public procurement; social and environmental issues.

\section{Introdução}

São cada vez maiores o apoio e o incentivo à licitação sustentável (compra pública sustentável - CPS), incorporando aos critérios tradicionais das compras públicas, geralmente apoiados no menor preço, fatores socioambientais que, além da racionalização dos custos, possibilitem alavancar e promover certos grupos sociais desfavorecidos ou que se diferenciam pelos critérios ambientais que envolvem o processo produtivo. O conceito de compras sustentáveis busca incorporar simultaneamente critérios de eficiência econômica, social e ambiental, algo alinhado à necessidade de se avançar de uma perspectiva seccionada e reducionista para uma visão complexa, que busca entender a realidade numa amplitude de contornos, o que tende a gerar resultados que superam as fronteiras tradicionais de cada política pública, gerando sinergia capaz de potencializá-las.

A relevância do tema pôde ser verificada, por exemplo, quando, em 2000, na $3^{\text {a }}$ Conferência Europeia sobre Cidades e Municípios Sustentáveis, em que 250 líderes municipais, de 36 países europeus e regiões vizinhas, preocupados com o tema sustentabilidade, aprovaram o texto da Convocatória de Hannover, o qual afirma que os líderes municipais europeus "(...) devem ter consciência sobre o poder de compra das autoridades locais no mercado e usá-lo para direcionar o desenvolvimento para soluções social e ambientalmente saudáveis" (Arnold e Whitford, 2006).

A União Europeia é bastante atuante em se tratando de licitação sustentável, o que pôde ser verificado em março de 2004, quando passou a adotar critérios ambientais em seus procedimentos licitatórios seguindo a recomendação da Organização para a Cooperação e Desenvolvimento Econômico (Ocde), que em 31 de janeiro de 2002 sugeria que fossem considerados os aspectos ambientais na licitação pública de produtos e serviços. Assim, vem crescendo na Europa o número de países que adotam critérios de licitação sustentável, entre eles, Reino Unido, Países Baixos, Noruega, Suécia, Áustria e Suíça (Korkmaz, 2010). 
O órgão Iclei, siga em inglês para Local Governments for Sustainability (Governos Locais pela Sustentabilidade, no Brasil), tem organizado seminários nacionais e internacionais, promovido pesquisas e campanhas com municípios com o objetivo de estabelecer diretrizes para as compras públicas sustentáveis. Diretrizes que servem como modelo para outros órgãos de governo. Por exemplo, podemos citar a Agenda 21 nacional voltada para compras públicas sustentáveis, bem como a Lei Federal no 11.947/2009, que determina a utilização de, no mínimo, 30\% dos recursos repassados pelo Fundo Nacional de Desenvolvimento da Educação (FNDE) para alimentação escolar, na compra de produtos da agricultura familiar. Ações como estas, que buscam a criação de mercado para produtos sustentáveis e o estabelecimento de novos parâmetros para o setor privado, fomentam a questão em âmbito nacional e integram e potencializam diferentes políticas públicas, geralmente dispersas e, por isso, enfraquecidas.

Diante do exposto, a questão central e coerente com o papel do setor público comprometido com a promoção da sustentabilidade, em seu sentido mais amplo e irrestrito, é alterar o paradigma de compras públicas vigente, reduzido a critérios de preço e qualidade, desprezando critérios de promoção social e de preservação ambiental. Fato que poderá impactar diretamente nos padrões de produção e impulsionar determinadas organizações que se destacam pela inclusão social e pelo cuidado ambiental. No Brasil, calcula-se que as compras públicas movimentam recursos estimados de até 20\% do Produto Interno Bruto (PIB), segundo dados do Ministério do Planejamento, Orçamento e Gestão (MPOG). Apesar da ainda baixa participação no valor total das compras públicas, as aquisições que incorporaram critérios sociais e ambientais em seus editais cresceram significativamente $236 \%$ entre os anos de 2010 e 2012 (MPOG, 2012).

Destarte, este artigo tem como objetivo esclarecer como o Estado tem contribuído para o desenvolvimento sustentável fazendo uso de seu poder de compra. Buscando comparar práticas e regulamentações a esse respeito, entre os estados do Sul do Brasil e o de São Paulo (pioneiro nesta abordagem), no sentido de entender os principais avanços e desafios, este estudo pode ser entendido como de natureza qualitativo-descritiva, bibliográfico e documental (Godoy, 1995, 2010). São apresentados casos de compras públicas sustentáveis, conforme levantamento em editais e legislações, portarias, regulamentos e decretos estaduais, assim como indícios em editais de licitação que complementam as normas nacionais já existentes. Esta pesquisa documental foi realizada, de forma sistemática, principalmente em meio eletrônico, entre 2011 e 2013.

O presente trabalho está estruturado em sete seções, contando com a introdução. A segunda parte trata da ampliação do entendimento do conceito de sustentabilidade, seguida de uma revisão bibliográfica, na terceira seção, sobre compras públicas e seus aspectos sustentáveis. A quarta seção refere-se às compras públicas sustentáveis e seus principais objetivos e obstáculos, além de serem apresentados exemplos de como as compras sustentáveis vêm se efetivando em alguns estados brasileiros. Na quinta seção, é apresentada a metodologia e, na seguinte, as análises e discussões são comentadas; por último, são tecidas as considerações finais. 


\section{Ampliando o conceito de sustentabilidade}

O desenvolvimento sustentável é um conceito que se encontra em expansão, ampliando frequentemente suas fronteiras de forma a conseguir abarcar a complexidade que envolve a temática, que por seu caráter multidisciplinar não pode ser reduzida a uma única dimensão, sob o risco de abandonar seu caráter sustentável distante da realidade concreta.

Os avanços tecnológicos advindos desde a Revolução Industrial, a política de crescimento econômico incondicional e o aumento da população trouxeram em seu bojo importantes reflexos para o meio ambiente e para a sociedade. O modelo de desenvolvimento atual caracteriza-se pela exploração descontrolada e irresponsável dos recursos naturais, com a finalidade de alimentar um padrão de consumo irracional, que se efetiva de forma assimétrica em diferentes partes do mundo e dentro de cada nação. Enquanto uns transferem para o consumo a própria razão de existência, outros nem sequer conseguem manter as condições materiais elementares à própria sobrevivência. Contudo, o problema do consumo parece reduzir-se a uma questão meramente individual, distante de qualquer envolvimento institucional capaz de mexer nas estruturas vigentes e torná-las mecanismos efetivos de inclusão social e indução de comportamentos socioeconômicos sustentáveis.

A ideia moderna de sustentabilidade encontra no ensaio de Boulding (1966) um importante marco no aprofundamento da temática e consolidou-se sobremaneira no trabalho desenvolvido a partir do debate do Clube de Roma de 1972, que resultou na publicação The limits to growth (Meadows et al., 1972), em que se problematizou a questão do crescimento acelerado da população mundial e do consumo em contraste com as limitações dos recursos naturais no planeta. Ainda em 1972, ocorreu a Conferência de Estocolmo sobre o Ambiente Humano das Nações Unidas, onde se deu, pela primeira vez, um debate em nível mundial sobre os problemas ambientais globais.

O conceito de Desenvolvimento Sustentável foi cunhado pela Comissão Mundial sobre Meio Ambiente e Desenvolvimento (World Commission on Environment and Development - WCED), cujo relatório Our common future, conhecido como Relatório de Brundtland, de 1987, apresentou a necessidade de repensar os modelos de desenvolvimento socioeconômicos vigentes. A Comissão estabeleceu conexão entre os sistemas econômico, social e ambiental e político destacando a equidade intrageracional bem como a equidade intergeracional, e sugeriu a natureza global das políticas econômicas e as reformas institucionais necessárias. A WCED (1987:43) deu-nos a definição padrão de desenvolvimento sustentável:

O desenvolvimento que procura satisfazer as necessidades da geração atual, sem comprometer a capacidade das gerações futuras de satisfazerem as suas próprias necessidades, significa possibilitar que as pessoas, agora e no futuro, atinjam um nível satisfatório de desenvolvimento social e econômico e de realização humana e cultural, fazendo, ao mesmo tempo, um uso razoável dos recursos da terra e preservando as espécies e os habitats naturais. (tradução nossa)

Esta definição passou a ser amplamente adotada, mas também criticada pela falta de clareza, ainda que não haja consenso sobre uma temática envolta em tamanha complexidade, 
como é a questão da sustentabilidade, que é vista aqui como uma propriedade do sistema, sendo desenvolvimento sustentável entendido como atividades políticas destinadas a reforçar essa propriedade. A diferença é descrita por Dovers e Handmer (1992):

Sustentabilidade é a capacidade de um sistema natural, humano ou misto para resistir ou adaptar-se, sobre uma escala de tempo indeterminado, a mudanças endógenas ou exógenas percebidas como ameaças. Desenvolvimento sustentável é um caminho de mudança endógena deliberada (melhoria) que mantém ou aumenta esse atributo em algum grau, ao responder às necessidades da população atual.

Sustentabilidade é, portanto, condição a longo prazo e desenvolvimento sustentável é a variável de processo de aproximação a essa condição. A agenda da WCED foi refinada por 179 países na Conferência das Nações Unidas sobre Meio Ambiente e Desenvolvimento em 1992 (Unced), a partir do qual fluiu uma série de documentos: a Declaração do Rio, a Agenda 21, as convenções sobre alterações climáticas, biodiversidade e desertificação, uma declaração sobre as florestas, entre outras; e mais recentemente, a Rio +20 . Novas configurações institucionais e o contínuo desenvolvimento de acordos e protocolos preveem maior evolução da política internacional que se estabelece.

Para atingir a sustentabilidade, o homem não deveria em sua totalidade explorar a natureza para além da sua capacidade de renovação, o que implica adotar novos estilos de vida e novos caminhos para o desenvolvimento, menos concentrado no bem-estar pessoal e no lucro, e mais centrado no bem-estar coletivo e no respeito pela dignidade humana e pela natureza (Szanto, 1998).

Ignacy Sachs (2010) tem sido um dos principais autores responsáveis não só pela exploração do tema do desenvolvimento sustentável, como vem enriquecendo e ampliando suas fronteiras tradicionais incorporando novos elementos e entendimentos dessa realidade. Uma das suas contribuições mais importantes é a expansão da visão de eficiência, ultrapassando o domínio absoluto da perspectiva produtivista, aliando o compromisso à eficiência social, a qual é avaliada pela capacidade de proporcionar trabalho de qualidade, bem-estar social e dignidade para todos os envolvidos no processo, e ainda incorporar a ecoeficiência, ou seja, produzir mais e melhor com o menor uso de recursos naturais e menos emissão de resíduos.

Ainda que a ampliação do conceito de eficiência possa gerar custos adicionais, contrariando a lógica do modelo tradicional, só o alinhamento entre eficiência econômica, ambiental e social se justifica e pode apontar para um futuro realmente sustentável e humanamente decente.

\section{Compra pública e seu caráter sustentável}

Câmara e Frossard (2010) argumentam que a perspectiva acadêmica tradicional, orientada preponderantemente por uma perspectiva econômica, vê as compras apenas como instrumen- 
to que supre a administração dos bens necessários à execução das políticas públicas e ao seu funcionamento regular. Assim, para realizar suas atividades finalísticas, ou não, a administração pública realiza compras, que são suporte à atuação governamental. Além desse suporte à atuação governamental, as compras também podem ser vistas como um instrumento de política pública, por conter funções de ordem econômica e social.

De acordo com Mohan (2010), a compra pública, de maneira clássica, é definida como a implementação de obras, bens e serviços nas melhores condições possíveis, tendo como parâmetros primordiais o preço e a qualidade. Neste estudo, almeja-se discutir os critérios tradicionais, numa visão ampliada da função do Estado que não se limita a racionalizar custos, mas a potencializar os benefícios sociais de suas políticas. Assim, além do suprimento dos bens e serviços necessários à execução das políticas públicas e ao funcionamento regular do Estado, a expansão dos critérios tradicionais das compras públicas, incorporando elementos de impacto social e cuidado com o meio ambiente, parece ser pertinente e legítima ao potencializar as ações dos governos fundamentadas na inclusão social e na preservação ambiental.

A compra, de uma perspectiva mais genérica, realiza-se por intermédio de um contrato bilateral, com direitos e obrigações e com pagamento de preço, como contraprestação da transferência do domínio do bem (Câmara e Frossard, 2010). Entretanto, é prudente, ao se falar do conceito de compras governamentais, que se fale anteriormente das leis envolvidas.

Compra pública encontra-se definida no art. 6o da Lei de Licitações e Contratos da Administração Pública, Lei no 8.666/1993, como “toda aquisição remunerada de bens para o fornecimento de uma só vez ou parceladamente". As compras e contratações governamentais compreendem procedimentos com características e componentes de caráter comercial, envolvendo a negociação de propostas de preço e de caráter jurídico-legal, sujeitando-se a controles, à interposição de recursos e à aplicação de sanções administrativas (Fernandes, 2005). Verifica-se que, no Brasil, esse setor de compras governamentais movimenta recursos estimados em 20\% do PIB, segundo dados do MPOG (2012).

Nesse sentido, é enorme a responsabilidade do gestor público encarregado de definir as regras do jogo para assegurar a livre concorrência, sem perder de vista o interesse do governante em dispor do melhor produto/serviço pelo menor preço possível. É nesse contexto de compras públicas que a escala das compras governamentais produz um efeito cascata sobre os fornecedores, multiplicando investimentos na direção da sustentabilidade, podendo transformar-se numa ferramenta importante de promoção do desenvolvimento sustentável, sob indução da esfera pública, mas com repercussão estendida a toda a sociedade, nomeadamente com impactos diretos na iniciativa privada (Souza e Olivero, 2010:4).

Considerando o consumo vultoso do Estado e sua representatividade na economia nacional, associado ao debate que condiciona desenvolvimento à preocupação com a questão da sustentabilidade econômica, social e ambiental, é mister reescrever o conceito de compras públicas incorporando novos elementos, tais como: satisfação das necessidades humanas, preocupação com futuras gerações e preocupação com a distribuição social da renda.

Tentando definir um conceito bastante complexo e atual, a comunidade europeia baseia-se no conceito de compras públicas sustentáveis estabelecido pelo documento Procuring 
the future, de junho de 2006, elaborado pela força-tarefa britânica para compras públicas sustentáveis (UK Sustainable Procurement Task Force):

A Compra Pública Sustentável ou Licitação Sustentável deve considerar as consequências ambientais, sociais e econômicas dos seguintes aspectos: elaboração de projeto; utilização de materiais renováveis; métodos de produção; logística e distribuição; uso, operação, manutenção, reúso; opções de reciclagem; e o comprometimento dos fornecedores em lidar com essas consequências ao longo de toda a cadeia produtiva. (UK Sustainable Procurement Task Force, 2006; tradução nossa)

Segundo Birdeman e colaboradores (2008), a licitação sustentável (compra sustentável) é uma solução para integrar considerações ambientais e sociais em todos os estágios do processo da compra e contratação dos agentes públicos com o objetivo de reduzir impactos à saúde humana, ao meio ambiente e aos direitos humanos. A compra pública sustentável permite o atendimento das necessidades específicas dos consumidores finais por meio da compra do produto/serviço que oferece o maior número de benefícios para o ambiente e a sociedade.

Por intermédio da compra sustentável, as organizações públicas poderiam usar de seu poder de compra para dar um sinal ao mercado a favor da sustentabilidade, passando a escolher bens e serviços, e aliando, aos critérios atuais, quesitos socioambientais:

จ Razões econômicas: a melhor relação custo-benefício, preço, qualidade, disponibilidade, funcionalidade;

v Aspectos ambientais, contratos públicos ecológicos, ou seja: os impactos do produto e/ou serviço em seu ciclo de vida, produção ou descarte sobre o meio ambiente; e

- Aspectos sociais: efeitos de decisões de compra em questões como erradicação da pobreza, equidade internacional na distribuição dos recursos, condições de trabalho, direitos humanos.

A CPS, conforme Mohan (2010), também leva em consideração questões como: extração de recursos naturais e consumo, fabricação e produção, transporte e logística, design de produtos, ativos, uso e manutenção, opções de reciclagem e eliminação, direitos dos trabalhadores e das condições, corrupção, concorrência desleal e comportamento ético.

Segundo Adjei (2010), apoiadas nos critérios de sustentabilidade, as compras públicas trariam os seguintes benefícios: (a) redução de impactos ambientais adversos decorrentes de contratos públicos; (b) utilização mais eficiente dos recursos públicos; (c) estímulo aos mercados locais e globais à inovação de produtos e serviços sustentáveis para compradores, sejam públicos e/ou privados; (d) melhorar o comportamento "ético" dos fornecedores/empreiteiros, especialmente, e do público em geral; (e) melhorar as condições de trabalho, saúde e segurança e as condições dos grupos desfavorecidos no país que aplica a Compra Pública Sustentável. 


\section{Obstáculos à Compra Pública Sustentável}

Até a presente data, o potencial das CPS tem sido apenas parcialmente explorado. Levandose em consideração que atender aos critérios socioambientais pode implicar, em certos casos, custos adicionais, tal fato nem sempre é facilmente acolhido dentro da lógica dominante, calcada no imediatismo e na percepção desarticulada entre as partes.

Korkmaz (2010), ao tratar dos limitadores e impulsionadores das compras sustentáveis, argumenta que as principais barreiras para a realização de contratos sustentáveis parecem ser: (1) o hábito e a dificuldade de mudar o comportamento de compra; (2) a falta de fornecedores de bens ou serviços "sustentáveis"; (3) a complexidade de comparar custo/valor de avaliação real do dinheiro; (4) a dificuldade de incluir fatores mais amplos que as considerações ambientais; e (5) a percepção de que o processo e os resultados são mais dispendiosos e demorados.

Preuss e Walker (2011) apresentam alguns impedimentos psicológicos ao funcionamento da CPS: (1) fatores individuais de natureza cognitiva e afetiva que interagem com (2) fatores organizacionais, tais como controle gerencial, estrutura organizacional e cultura organizacional. Por sua vez, a interação destas barreiras é formada por (3) processos de adaptação em pequenos grupos de trabalho, que podem fornecer ancoragem para os indivíduos, mas também produzir pressões de conformidade.

Outros impedimentos psicológicos seriam: (4) a adaptação de processos na organização, como a resistência interna e problemas de coordenação em grandes organizações descentralizadas e, também, (5) os processos de adaptação entre as organizações, compostos por uma série de pressões isomórficas, problemas de coordenação horizontal entre os diferentes organismos públicos e vertical entre os vários membros da cadeia de suprimentos do setor público.

Um importante limite à CPS é a crônica corrupção no setor público brasileiro. O Brasil

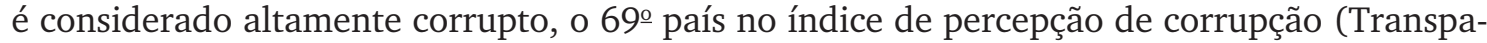
rency International, 2012). Dematté (2009) argumenta que a mudança de postura do poder público é fundamental nessa seara, pois a manutenção de uma atitude omissa ou propositalmente direcionada a atender interesses de terceiros, que não a sociedade, poderá incutir em toda a comunidade a sensação de que as infrações e as sanções não passam de um discurso falacioso, sem contar a dificuldade de se legitimar práticas de compras públicas sustentáveis em um contexto de descrença.

\section{Abordagem metodológica}

Visando a consecução do objetivo do presente estudo, qual seja, verificar como o Estado tem compreendido suas ações de sustentabilidade por meio de seu poder de compra, buscou-se comparar as práticas contemporâneas e a regulamentação a esse respeito, considerando os estados brasileiros de São Paulo, Santa Catarina, Paraná e Rio Grande do Sul, escolhas feitas 
de forma arbitrária, mas que refletem um escopo particular de comparação entre o Sul e o estado pioneiro na abordagem do assunto.

Foi utilizada pesquisa bibliográfica, na qual se verificaram casos de compras públicas sustentáveis em vigor, bem como pesquisa documental em editais eletrônicos e em legislações concernentes ao assunto nos referidos estados. A coleta de dados foi realizada, de forma sistemática, em meio eletrônico contemplando o primeiro semestre de 2011 e posteriormente replicada no primeiro semestre de 2013, abrangendo os editais publicados nas modalidades pregão eletrônico, tomada de preços e concorrência pública até o momento da realização da pesquisa.

Buscou, assim, as legislações, portarias, regulamentos e decretos estaduais, que complementassem as normativas nacionais, bem como indícios em editais de licitação que remetessem à problemática da compra pública sustentável. Essa busca sistemática, dentre os referidos documentos, teve como critério principal a existência de indicativos de práticas condizentes ao discurso da sustentabilidade, considerando as dimensões social, ambiental e econômica, e teve como critério de seleção os termos, a saber: social, sustentável, solidário, ambiente, conservação/preservação, responsabilidade ambiental, trabalho infantil e escravidão. Justificando a opção pela pesquisa documental, argumenta-se que ela permitiu acrescentar a dimensão do tempo ao fenômeno da sustentabilidade atrelado às compras governamentais, uma vez que esse é um fenômeno novo e carente de reflexões. Ou seja, tal abordagem mostrou-se adequada ao anseio de averiguar o estágio em que se encontram as CPS nos estados brasileiros selecionados para o estudo (Cellard, 2008).

\section{Análise e discussão}

Alguns exemplos referentes às licitações sustentáveis encontrados na pesquisa são apresentados durante esta seção. O governo federal mexicano, que integra um grupo de "compras públicas verdes" criado no âmbito do Acordo Norte-Americano de Livre-Comércio (North American Free Trade Agreement - Nafta), apresenta um programa de gestão ambiental pública, que inclui a capacitação de funcionários, reciclagem, economia de energia, entre outros.

O Reino Unido realiza a CPS há mais de uma década, apresentando um programa intenso de treinamento dos compradores públicos, em que o tema sustentabilidade é bastante discutido. $\mathrm{O}$ assunto sustentabilidade é relevante quando há necessidade de criar uma estratégia para a organização, no mapeamento de impactos e riscos para o mercado; ou, ainda, na análise dos riscos associados ao ciclo de vida dos produtos. Nesses termos, os avanços foram tão acima do esperado que já preveem compensação salarial para o bom desempenho dos funcionários de acordo com as metas estabelecidas em relação às compras sustentáveis.

O órgão inglês Iclei é responsável pelo guia sobre critérios de sustentabilidade no processo de compras públicas, muito utilizado por autoridades públicas em toda a Europa. Percebe-se que o tema CPS é mais desenvolvido e praticado na Europa, porém, mesmo que em menor grau, o Brasil possui iniciativas relevantes nesse sentido. O quadro 1 aponta algumas dessas movimentações em âmbito legal. 
A partir da análise do quadro, verifica-se que a legislação brasileira referente à questão socioambiental modifica-se com o passar do tempo e tem suas primeiras movimentações na década de 1990 (Birdeman et al., 2008), indicando uma grande oportunidade a ser trabalhada pelos governos no que tange a essa problemática de regulamentação e controle.

No Brasil, a Lei no 8.666, de junho de 1993, é a principal norteadora dos processos de compras públicas, a qual foi alterada, pela redação conferida ao art. $3^{\circ}$ da mesma lei, pela Lei no 12.349, de 15 de dezembro de 2010, que modificou radicalmente o quadro jurídico e operacional das licitações públicas no Brasil, obrigando todos os entes da Federação a promoverem licitações públicas sustentáveis.

\section{Quadro 1}

\section{Evolução das políticas públicas em nível nacional e sustentabilidade}

\begin{tabular}{|c|c|}
\hline 2010 & $\begin{array}{l}\text { No ano de 2010, o Congresso Nacional aprovou uma modificação na redação do art. 3ํ, caput, da Lei no } \\
\text { 8.666, que instituiu o marco legal das licitações sustentáveis no âmbito da Administração Pública brasileira. }\end{array}$ \\
\hline 2009 & $\begin{array}{l}\text { Lei no } 11.947 / 2009 \text { altera dispositivos da Lei no } 8.666 \text { incluindo licitações públicas sustentáveis em âmbito } \\
\text { federal. Dispõe sobre o atendimento da alimentação escolar e do programa dinheiro direto na escola aos } \\
\text { alunos da educação básica. }\end{array}$ \\
\hline 2007 & $\begin{array}{l}\text { O Poder Executivo encaminhou, para a Câmara dos Deputados, projeto de lei que busca alterar dispositivos } \\
\text { da Lei ํo } 8.666 \text {, de } 21 \text { de junho de 1993, que regulamenta o art. 37, inciso XXI da Constituição, para inclusão } \\
\text { de critérios de sustentabilidade ambiental nas contratações públicas. }\end{array}$ \\
\hline 2002 & $\begin{array}{l}\text { Aprovação do Decreto no 4.131/2002, que dispõe sobre medidas emergenciais de redução do consumo de } \\
\text { energia elétrica no âmbito da administração pública federal. }\end{array}$ \\
\hline 1998 & $\begin{array}{l}\text { No nível da Presidência da República, foi aprovado o Decreto ํo 2.783, de } 17 \text { de setembro de 1998, proibindo } \\
\text { entidades do governo federal de comprar produtos ou equipamentos contendo substâncias degradadoras } \\
\text { da camada de ozônio. Porém, esse decreto é desconhecido pela maioria das entidades e é ignorado muitas } \\
\text { vezes na prática das licitações. }\end{array}$ \\
\hline 1990 & $\begin{array}{l}\text { O Decreto no 99.658/1990 regulamenta, no âmbito da administração pública federal, o reaproveitamento, } \\
\text { a movimentação, a alienação e outras formas de desfazimento de material. }\end{array}$ \\
\hline
\end{tabular}

Fonte: Elaborado pelos autores com base em Birdeman e colaboradores (2008) e nos dados da pesquisa.

Em âmbito estadual, mais precisamente nos estados brasileiros de São Paulo, Santa Catarina, Rio Grande do Sul e Paraná, buscou-se verificar as modificações nas legislações que fossem ao encontro da CPS. Essa busca resultou em informações importantes que foram compiladas no quadro 2 . 
Quadro 2

Critérios de sustentabilidade e legislação estadual: SP e PR

\begin{tabular}{|c|c|c|}
\hline ESTADOS & LEGISLAÇÃO & CRITÉRIOS DE SUSTENTABILIDADE \\
\hline \multirow[t]{3}{*}{ Paraná } & $\begin{array}{l}\text { Lei no } 15.608 \text { de 16/8/2007, art. } \\
\text { 5o }\end{array}$ & $\begin{array}{l}\text { A realização de contratos e convênios, subordinados a esta lei, está } \\
\text { juridicamente condicionada: I - aos princípios universais da isonomia e } \\
\text { sustentabilidade ambiental. }\end{array}$ \\
\hline & $\begin{array}{l}\text { Lei Complementar no } 59 \text {, de } \\
1 / 10 / 1991\end{array}$ & $\begin{array}{l}\text { Lei dos Royalties Ecológicos ou ICMS Ecológico, que repassa recursos } \\
\text { financeiros aos municípios que abrigam em seus territórios Unidades de } \\
\text { Conservação ou áreas protegidas, ou ainda mananciais para abastecimento } \\
\text { de municípios vizinhos. }\end{array}$ \\
\hline & Lei no $16.751,29 / 12 / 2010$ & $\begin{array}{l}\text { Lei da merenda escolar orgânica institui, no âmbito do sistema estadual } \\
\text { de ensino fundamental e médio, a merenda escolar orgânica. }\end{array}$ \\
\hline \multirow[t]{7}{*}{ São Paulo } & Lei nº 12.684, 26/6/2007 & $\begin{array}{l}\text { Proíbe o uso, no estado de São Paulo, de produtos, materiais ou artefatos } \\
\text { que contenham quaisquer tipos de amianto ou asbesto ou outros minerais } \\
\text { que, acidentalmente, tenham fibras de amianto na sua composição. }\end{array}$ \\
\hline & Lei no $12.226,11 / 1 / 2006$ & Institui a Política Estadual de Apoio ao Cooperativismo. \\
\hline & Lei no 12.047, 21/9/2005 & $\begin{array}{l}\text { Institui Programa Estadual de Tratamento e Reciclagem de Óleos e } \\
\text { Gorduras de Origem Vegetal ou Animal e Uso Culinário. }\end{array}$ \\
\hline & Lei no $11.878,19 / 1 / 2005$ & Institui o "Selo Verde Oficial do Estado de São Paulo". \\
\hline & Lei no 10.996, 21/12/2001 & $\begin{array}{l}\text { Dispõe sobre a proibição da produção e consumo de brinquedos que } \\
\text { imitem armas de fogo em todo o território do Estado. }\end{array}$ \\
\hline & Lei nº 10.888, 20/9/2001 & $\begin{array}{l}\text { Dispõe sobre o descarte final de produtos potencialmente perigosos } \\
\text { do resíduo urbano que contenham metais pesados e dá outras } \\
\text { providências. }\end{array}$ \\
\hline & Lei no $10.761,23 / 1 / 2001$ & $\begin{array}{l}\text { Dispõe sobre a proibição da utilização de alimentos transgênicos na } \\
\text { composição da merenda fornecida aos alunos dos estabelecimentos de } \\
\text { ensino oficiais do estado de São Paulo. }\end{array}$ \\
\hline
\end{tabular}

Fonte: Elaborado pelos autores com base nos dados da pesquisa.

Um primeiro indício verificado nessa mesma busca foi a percepção de ser este um movimento muito incipiente na região sul, devido ao baixo número de iniciativas encontradas.

Foram identificadas, em São Paulo, iniciativas como o Cadastro estadual das organizações que comercializam produtos e subprodutos de origem nativa da flora brasileira (Cadmadeira); o Decreto no 48.138/2003, que dispõe sobre a obrigação de adoção de medidas de redução de consumo e racionalização de água no âmbito da administração pública direta e indireta; e o Decreto $\mathrm{n}^{\circ}$ 41.629/1997, que dispõe sobre a proibição à administração direta e indireta de adquirir produtos ou equipamentos contendo substâncias que destroem a camada de ozônio. 
O Paraná, dentre os estados do Sul, segundo dados da pesquisa, foi o único que apresentou alguma legislação específica que levasse em consideração critérios específicos de sustentabilidade. Esse é o caso da Lei no 15.608 , de 16 de agosto de 2007, que subordina contratos e convênios aos princípios da isonomia e da sustentabilidade ambiental. O Paraná também foi o pioneiro em implementar uma legislação que premiasse, com o repasse de recursos financeiros, os municípios que abrigam Unidades de Conservação ou áreas protegidas, ou ainda, mananciais para abastecimento de municípios vizinhos, qual seja, o ICMS Ecológico - Imposto sobre Circulação de Mercadorias e Prestação de Serviços. Há que se ressaltar o pioneirismo do estado, que demarcou um modelo seguido por outros estados, sendo São Paulo o segundo a implementar tal legislação.

Um dos maiores avanços em termos de critérios com impactos sociais foi a Lei Federal no 11.947/2009, que determina a utilização de, no mínimo, 30\% dos recursos repassados pelo FNDE para alimentação escolar, na compra de produtos da agricultura familiar, priorizando os assentamentos de reforma agrária, as comunidades tradicionais indígenas e quilombolas. O estado do Paraná instituiu essa prática em 29 de dezembro de 2010, sob a Lei № 16.751. Critérios como esse ainda são raros, e fazem com que a questão social seja a mais negligenciada quando se fala em compras públicas sustentáveis que ainda tendem a se restringir a critérios estritamente ambientais, o que limita enormemente o potencial de inclusão social das políticas de compras públicas.

Apesar de não ter sido encontrada legislação estadual específica, alguns municípios têm normas que tratam do assunto. Em Porto Alegre, no ano de 2007, o Decreto no 15.699/2007 estabeleceu normas para aquisição de produtos e subprodutos florestais de origem nativa ou não. Cidades do sul, tais como Florianópolis (SC), Criciúma (SC) e Palmeira (PR), incentivaram a compra de produtos alimentícios orgânicos para a merenda escolar, os chamados programas de merendas ecológicas. Dessa forma, empreenderam parcerias entre prefeituras e pequenos produtores familiares, apoiando a produção agrícola orgânica e familiar, garantindo assim, como diria Mohan (2010), benefícios financeiros máximos para a comunidade como um todo.

O quadro 3 compila os principais indícios referentes à prática de sustentabilidade encontrados nas licitações públicas, ou seja, o que está sendo realmente realizado quando se trata de compras públicas sustentáveis. Como já acontecera com a legislação, quando se trata dos indícios de sustentabilidade encontrados, o estado do Paraná foi o único, dentre os estados do Sul, que apresentou diferenciação, por exemplo, a exigência de cumprimento ao disposto no Decreto Estadual no 6.252/2006, que versa sobre critérios de qualidade ambiental e sustentabilidade socioambiental. Todavia, a região Sul apresenta-se, ainda, em fase inicial, se comparada a São Paulo.

Além da declaração em conformidade com a legislação nacional, encontrou-se a exigência, aos fornecedores, de se elaborar e manter programa interno de treinamento para redução de consumo de energia elétrica e de água, bem como para redução da produção de resíduos sólidos etc. Ainda que estes quesitos não sejam encontrados em todos os editais, demonstram certo avanço, que poderá expandir-se no futuro (Preuss e Walker, 2011). 
A seguir são apresentados, por meio de um quadro panorâmico, os critérios de sustentabilidade encontrados nas licitações públicas de cada um dos estados pesquisados, ou seja, São Paulo, Rio Grande do Sul, Paraná e Santa Catarina, além da modalidade de licitação adotada.

Quadro 3

Critérios de sustentabilidade encontrados em licitações públicas dos estados de SP, RS, PR e SC

\begin{tabular}{|c|c|}
\hline ESTADOS & CRITÉRIOS DE SUSTENTABILIDADE INSERIDOS NOS EDITAIS \\
\hline \multirow[t]{2}{*}{$\begin{array}{l}\text { Santa } \\
\text { Catarina }\end{array}$} & $\begin{array}{l}\text { Declaração de cumprimento ao disposto no inciso XXXIII do art. 7o da Constituição Federal, que versa } \\
\text { sobre a proibição de trabalho noturno, perigoso ou insalubre a menores, nos termos da Lei no } 9.854 \text {, } \\
\text { de } 27 / 10 / 99 \text {. }\end{array}$ \\
\hline & $\begin{array}{l}\text { Declaração emitida pelo licitante, de que não emprega menor de dezoito anos em trabalho noturno, } \\
\text { perigoso ou insalubre e não emprega menor de dezesseis anos. Ressalva: emprega menor, a partir } \\
\text { de quatorze anos, na condição de aprendiz. }\end{array}$ \\
\hline \multirow[t]{5}{*}{ Paraná } & $\begin{array}{l}\text { Declaração de cumprimento ao disposto no Decreto Estadual no 6.252/06, de } 22 \text { de março } \\
\text { de 2006, que versa sobre critérios de qualidade ambiental e sustentabilidade socioambiental, } \\
\text { respeitando as normas de proteção do meio ambiente; }\end{array}$ \\
\hline & $\begin{array}{l}\text { Declaração de cumprimento ao disposto no inciso XXXIII do art. 7ํ da Constituição Federal, que versa } \\
\text { sobre a proibição de trabalho noturno, perigoso ou insalubre a menores, nos termos da Lei no } 9.854 \text {, } \\
\text { de } 27 / 10 / 99 ;\end{array}$ \\
\hline & $\begin{array}{l}\text { Declaração emitida pelo licitante de inexistência de fato impeditivo em atendimento ao inciso } \\
\text { XXXIII, do art. 7o da Constituição Federal; e de cumprimento dos critérios de qualidade ambiental e } \\
\text { sustentabilidade socioambiental; }\end{array}$ \\
\hline & $\begin{array}{l}\text { Declaração de cumprimento ao disposto no inciso XXXIII do art. 70 da Constituição Federal, que não } \\
\text { temos em nossos quadros menores de } 18 \text { (dezoito) anos executando trabalho noturno, insalubre } \\
\text { ou perigoso a menor de } 16 \text { (dezesseis) anos, executando qualquer trabalho, salvo na condição de } \\
\text { aprendiz, a partir de } 14 \text { (quatorze) anos; }\end{array}$ \\
\hline & $\begin{array}{l}\text { Declaração de cumprimento ao disposto no Decreto Estadual no 6.252/06, de } 22 \text { de março } \\
\text { de } 2006 \text {, que versa sobre critérios de qualidade ambiental e sustentabilidade socioambiental, } \\
\text { respeitando as normas de proteção do meio ambiente. }\end{array}$ \\
\hline \multirow[t]{2}{*}{$\begin{array}{l}\text { Rio Grande } \\
\text { do Sul }\end{array}$} & $\begin{array}{l}\text { Declaração pelo licitante de que não emprega menores de } 18 \text { anos em trabalho noturno, perigoso } \\
\text { ou insalubre e não emprega menores de } 16 \text { anos, ressalvando o menor, a partir de } 14 \text { anos, na } \\
\text { condição de aprendiz, em atendimento ao Decreto Federal } 4.358 / 2002 ;\end{array}$ \\
\hline & $\begin{array}{l}\text { Declaração firmada pelo responsável da própria empresa licitante de cumprimento ao disposto no inciso } \\
\text { XXXIII do art. } 7 \text { o da Const. Federal e inciso V, art. 27, da Lei Federal no 8.668/93, de que não emprega } \\
\text { menor de } 18 \text { anos em trabalho noturno, perigoso e insalubre e não emprega menor de } 16 \text { anos, } \\
\text { ressalvado, quando for o caso, o menor, a partir de } 14 \text { anos, na condição de aprendiz, nos termos do } \\
\text { modelo anexo ao Decreto Federal 4.358, de } 05 \text { de setembro de 2002, que regulamenta a Lei no } 9.584 \text {, } \\
\text { de } 27 \text { de outubro de } 2002 \text {. }\end{array}$ \\
\hline
\end{tabular}

MODALIDADE DE LICITAÇÃO.

Tomada de

Preço

Concorrência

Pública

Tomada de

Preço

Concorrência

Pública 


\begin{tabular}{|c|c|c|}
\hline ESTADOS & CRITÉRIOS DE SUSTENTABILIDADE INSERIDOS NOS EDITAIS & $\begin{array}{l}\text { MODALIDADE } \\
\text { DE LICITAÇÃO. }\end{array}$ \\
\hline São Paulo & $\begin{array}{l}\text { Tópico em edital com as Obrigações e Responsabilidades Específicas, quanto a Boas Práticas } \\
\text { Ambientais, que pede para elaborar e manter um programa interno de treinamento de seus } \\
\text { empregados para redução de consumo de energia elétrica, consumo de água e redução de produção } \\
\text { de resíduos sólidos, observadas as normas ambientais vigentes; Receber, da Contratante, informações } \\
\text { a respeito dos programas de uso racional dos recursos que impactem o meio ambiente. } \\
\text { Tópicos específicos a respeito do uso Racional da Água; Uso Racional de Energia Elétrica; Redução de } \\
\text { Produção de Resíduos Sólidos; } \\
\text { Poluição Sonora. } \\
\text { No site da bolsa eletrônica de compras - SP encontra-se um extenso catálogo de produtos com selo } \\
\text { verde - Produtos. Exemplos: Veículo bicombustível; Embalagem revestida em bopp; com certificação } \\
\text { ambiental fsc ou cerflor, entre outros; } \\
\text { Comunicado BEC (bolsa eletrônica) 05/2009, que versa sobre a preferência às cooperativas em } \\
\text { processos licitatórios, na modalidade Pregão Eletrônico, conta com a possibilidade para que as } \\
\text { Cooperativas exerçam o direito de preferência, quando a detentora da proposta de menor valor, } \\
\text { dentre aquelas cujos valores sejam iguais ou superiores até } 5 \% \text { (cinco por cento) ao valor da melhor } \\
\text { oferta classificada. }\end{array}$ & $\begin{array}{l}\text { Pregão } \\
\text { Eletrônico }\end{array}$ \\
\hline
\end{tabular}

Fonte: Elaborado pelos autores.

\section{Considerações finais}

Por ser um novo paradigma no setor público e envolver um tema de alta complexidade, as dúvidas e imprecisões são recorrentes nas CPS. Elas ainda requerem um grande esforço em pesquisas e no desenvolvimento de tecnologias que garantam clareza de critérios, avaliação sistemática de seus resultados e impactos, transparência e controle público dos processos. Caso contrário, há o risco de que essa inovadora e indispensável iniciativa seja inviabilizada ou desvirtuada pelas estruturas institucionais tradicionais, que tendem a reproduzir a arquitetura socioeconômica vigente, numa lógica de cartas marcadas em que os vitoriosos se repetem historicamente e obstaculizam qualquer possibilidade de mudança mais profunda na estrutura social dominante, numa promíscua relação entre poder econômico e político.

Outra questão que merece ser revista é o próprio entendimento do conceito de sustentabilidade, que ainda tende a reduzir-se à questão ambiental, desconsiderando, ou até relegando a segundo plano, o compromisso com a dimensão social. Isso talvez se deva à importação do discurso do primeiro mundo, que já superou os problemas sociais mais graves e que tem na questão ambiental o seu grande desafio, distintamente dos países em desenvolvimento ou subdesenvolvidos, que ainda não conseguiram superar a pobreza.

É inegável a pressão de setores específicos da sociedade em impedirem critérios que possam beneficiar, por exemplo, cooperativas populares ou empreendimentos de economia 
solidária, pois esses critérios limitariam a participação de empresas tradicionalmente fornecedoras públicas, as quais não aceitam perder esse espaço.

As cooperativas solidárias, por seu compromisso com inclusão social, democracia interna e respeito ao meio ambiente, tornam-se particularmente alinhadas com o que se entende ser objeto de atenção e preocupação do Estado. Tanto que o possível privilégio auferido pelas cooperativas solidárias nas licitações públicas poderia se justificar. Ao integrar diferentes compromissos como erradicação da pobreza, preocupações ambientais, distribuição de renda, equidade e busca do bem comum, acabam por tratar os diferentes de forma diferenciada, atuando de forma a complementar o papel, supostamente, estatal.

Outra questão que merece destaque nesse universo é o elevado grau de corrupção nas licitações públicas, que está diretamente relacionado com o padrão de qualidade, de eficiência e de transparência dos mecanismos de controle, de regulação e de punição empregados pelo próprio Estado. A "grande" corrupção acontece, mais tipicamente, em licitações públicas, incluindo-se a fase política de definição de projetos e a execução física do que se licitou. Desse modo, pelo fato de as CPS estarem ainda em fase de demarcação, adverte-se para a necessidade de um melhor método de fiscalização. Assim, ao que tudo indica, esse segmento de compras públicas necessita ainda de um efetivo exercício do controle social e mesmo de pressão da sociedade para se transformar num efetivo mecanismo de transformação socioambiental (Abramo, 2014).

Por fim, neste trabalho verificou-se que o Estado tem contribuído para o desenvolvimento sustentável de forma bastante incipiente, com razoável destaque para o estado de São Paulo. Fato que abre caminho para novos estudos para investigar os motivos da ainda baixa aderência a essas políticas. Futuras investigações poderiam abordar o pensamento dos compradores públicos e legisladores sobre essa questão. Pois acredita-se que o Estado, por meio de seu grande poder como comprador, poderá reverter impactos sociais e ambientais advindos do processo produtivo, incentivando organizações que não tenham como princípio primeiro a busca do lucro individual.

\section{Referências}

ABRAMO, Claudio W. Corrupção e responsabilidade pública. Disponível em: <www.transparencia. org.br/docs/RespPub.pdf>. Acesso em: 12 jan. 2014.

ADJEI, Asafo B. Sustainable public procurement: a new approach to good governance. Seul: IPPC4, 2010. Disponível em: <www.ippa.org/IPPC4/Proceedings/07GreenProcurement/Paper7-10.pdf> . Acesso em: 21 jan. 2013.

ARNOLD, Richard; WHITFORD, Andrew B. Making environmental self-regulation mandatory. Global Environmental Politics, Massachussets, v. 6, n. 4, p. 1-12, nov. 2006.

BIRDEMAN, Rachel et al. Guia de compras públicas sustentáveis: uso do poder de compra do governo para a promoção do desenvolvimento sustentável. Rio de Janeiro: FGV, 2008. 
BOULDING, Kenneth E. The economics of the coming spaceship earth. In: JARRETT, Henry (Ed.). Environmental quality in a growing economy. Baltimore, MD: Resources for the Future; Johns Hopkins University Press, 1966. p. 3-14.

BRASIL. Decreto n ${ }^{\circ}$ 2.783, de 17 de setembro de 1998. Dispõe sobre proibição de aquisição de produtos ou equipamentos que contenham ou façam uso das Substâncias que Destroem a Camada de Ozônio - SDO. Diário Oficial [da] República Federativa do Brasil, Brasília, seção 1, pt. 1, p. 1, 18 set. 1998.

BRASIL. Decreto no 4.131/2002, de 14 de fevereiro de 2002. Dispõe sobre instituir normas para licitações e contratos da administração pública e dá outras providências. Diário Oficial [da] República Federativa do Brasil, Brasília, seção 1, pt. 1, p. 1, 15 fev. 2002.

BRASIL. Decreto n ${ }^{\circ} 99.658 / 90$, de 30 de outubro de 1990. Dispõe no âmbito da administração pública federal, o reaproveitamento, a movimentação, a alienação e outras formas de desfazimento de material. Diário Oficial [da] República Federativa do Brasil, Brasília, seção 1, pt. 1, p. 1, 30 out. 1990.

BRASIL. Lei no 8.666, de 21 de junho de 1993. Dispõe sobre normas gerais de licitações e contratos administrativos no âmbito dos Poderes da União, dos estados, do Distrito Federal e dos municípios. Diário Oficial [da] República Federativa do Brasil, Brasília, seção 3, pt, p. 1, 22 jun. 1993.

BRASIL. Lei $\mathrm{n}^{\circ}$ 9.854, de 27 de outubro de 1999. Dispõe sobre as alterações da Lei $\mathrm{n}^{\circ}$ 8.666, de 21/6/93, que regula o art. 37, inciso XXI, da Constituição Federal. Diário Oficial [da] República Federativa do Brasil, Brasília, seção 3, pt, p. 1, 22 jun. 1993.

CÂMARA, Leonor M.; FROSSARD, Leila B. de M. Poder de compras da administração pública federal: novas perspectivas para o debate acadêmico. In: ENCONTRO DE ADMINISTRAÇÃO PÚBLICA E GOVERNANÇA, 4., 2010, Vitória. Anais... Vitória: EnAPG, 2010. p. 2-16.

CELLARD, André. A análise documental. In: POUPART, Jean et al. A pesquisa qualitativa: enfoques epistemológicos e metodológicos. Petrópolis: Vozes, 2008.

DEMATTÉ, Flávio R. Punição de empresas por corrupção em licitações e contratos com o governo. In: CONGRESO INTERNACIONAL DEL CLAD SOBRE LA REFORMA DEL ESTADO Y DE LA ADMINISTRACIÓN PÚBLICA, 14., Salvador. Anais... Salvador: Clad, 2009. p.1-13.

DOVERS, Stephen R. Sustainability: demands on policy. Journal of Public Policy, Cambridge, v. 16, n. 3, p. 303-318, 1996.

DOVERS, Stephen R.; HANDMER, John. Uncertainty, sustainability and change. Global environ. Change, v. 4, n. 2, p. 262-276, 1992.

FERNANDES, Ciro C. C. Abrangência, inserção e impacto transformador dos sistemas de compras eletrônicas na administração pública - análise do Siasg/Comprasnet. Revista do Serviço Público, Brasília, v. 56, n. 2, p. 195-216, abr./jun. 2005.

GODOY, Arilda S. Introdução à pesquisa qualitativa e suas possibilidades. Revista de Administração de Empresas, São Paulo, v. 35, n. 2, p. 57-63, abr. 1995.

IBGE. Fundação Instituto Brasileiro de Geografia e Estatística. Comentário. A economia brasileira no $4^{\circ}$ trimestre de 2012: visão geral. Disponível em: <http://tinyurl.com/cdo8e62>. Acesso em: 22 abr. 2013. 
KORKMAZ, Abdullah. Benefits and obstacles of environmental, social and sustainable procurement. Seul: IPPC4, 2010. Disponível em: <www.ippa.org/IPPC4/Proceedings/07GreenProcurement/ Paper7-2.pdf>. Acesso em: 21 jan. 2013.

MEADOWS, Donela H. et al. The limits to growth. Washington: Potomac Associates, 1972.

MOHAN, Veluppillai. Public procurement for sustainable development. Seul: IPPC4, 2010. Disponível em: <www.ippa.org/IPPC4/Proceedings/07GreenProcurement/Paper7-11.pdf>. Acesso em: 21 jan. 2013.

MPOG. Ministério do Planejamento, Orçamento e Gestão. Compras sustentáveis na administração pública ganham em eficiência econômica. Brasília: MPOG, 2012. Disponível em: <http://cpsustentaveis.planejamento.gov.br/?p=1897>. Acesso em: 21 jul. 2014.

PARANÁ. Lei 15.608, 16 de agosto de 2007. Estabelece normas sobre licitações, contratos administrativos e convênios no âmbito dos poderes do estado do Paraná. Diário Oficial [do] Estado do Paraná, Curitiba, seção 1, pt. 1, 18 ago. 2007.

PARANÁ. Lei 16.751, 29 de dezembro de 2010. Institui, no âmbito do sistema estadual de ensino fundamental e médio, a merenda escolar orgânica. Diário Oficial [do] Estado do Paraná, Curitiba, seção 1, pt. 1, 6 jan. 2011.

PARANÁ. Lei Complementar no 59, 1 de outubro de 1991. Dispõe sobre a repartição de 5\% do ICMS, a que alude o art. $2^{\circ}$ da Lei $n^{\circ} 9.491 / 90$, aos municípios com mananciais de abastecimento e unidades de conservação ambiental, assim como adota outras providências. Diário Oficial [do] Estado do Paraná, Curitiba, seção 1, pt. 1, 2 out. 1991.

PREUSS, Lutz; WALKER, Helen. Psychological barriers in the road to sustainable development: evidence from public sector procurement. Public Administration, Oxford, v. 89, n. 2, p. 493-521, jun. 2011.

SACHS, Ignacy. Desenvolvimento includente, sustentável e sustentado. São Paulo: Garamond, 2010.

SÃO PAULO. Decreto 53.336/2008, de 20 de agosto de 2008. Institui o Programa Estadual de Contratações Públicas Sustentáveis e dá providências correlatas. Diário Oficial do Estado, 20 de agosto de 2008. Disponível em: < http://www.comprassustentaveis.net/legislacao-1>. Acesso em: 24 mar. 2011.

SÃO PAULO. Decreto n 50.170/2005, de 4 de novembro de 2005. Institui o Selo Socioambiental no âmbito da administração pública estadual. Diário Oficial do Estado, 4 nov. 2005. Disponível em: <www.comprassustentaveis.net/legislacao-1>. Acesso em: 24 mar. 2011.

SÃO PAULO. Lei n ${ }^{\circ}$ 10.761, 23 de janeiro de 2001. Dispõe sobre a proibição da utilização de alimentos transgênicos na composição da merenda fornecida aos alunos dos estabelecimentos de ensino oficiais do Estado de São Paulo. Diário [do] Estado de São Paulo, São Paulo, seção 1, pt. 1, 23 jan. 2001.

SÃO PAULO. Lei no 10.888, 20 de setembro de 2001. Dispõe sobre o descarte final de produtos potencialmente perigosos do resíduo urbano que contenham metais pesados e dá outras providências. Diário [do] Estado de São Paulo, São Paulo, seção 1, pt. 1, 20 set. 2001. 
SÃO PAULO. Lei n ${ }^{\circ}$ 10.996, de 21 de dezembro de 2001. Dispõe sobre a proibição da produção e consumo de brinquedos que imitem armas de fogo em todo o território do Estado. Diário Oficial [do] Estado de São Paulo, São Paulo, seção 1, pt. 1, 22 dez. 2001.

SÃO PAULO. Lei n ${ }^{\circ} 11.878$, de 19 de janeiro de 2005. Dispõe sobre a instituição do Selo Verde Oficial do Estado de São Paulo. Diário Oficial [do] Estado de São Paulo, São Paulo, seção 1, pt. 1, 19 jan. 2005.

SÃO PAULO. Lei n ${ }^{\circ}$ 12.047, de 21 de setembro de 2005. Institui Programa Estadual de Tratamento e Reciclagem de Óleos e Gorduras de Origem Vegetal ou Animal e Uso Culinário. Diário Oficial [do] Estado de São Paulo, São Paulo, seção 1, pt. 1, 21 set. 2005.

SÃO PAULO. Lei n ${ }^{\circ}$ 12.226, de 11 de janeiro de 2006. Dispõe sobre a instituição da Política Estadual de Apoio ao Cooperativismo. Diário Oficial [do] Estado de São Paulo, São Paulo, seção 1, pt. 1,12 jan. 2006.

SÃO PAULO. Lei n ${ }^{\circ}$ 12.684, de 26 de julho de 2007. Dispõe sobre a proibição do uso de produtos, materiais ou artefatos que contenham quaisquer tipos de amianto ou asbesto. Diário Oficial [do] Estado de São Paulo, São Paulo, seção 1, pt. 1, 27 jul. 2007.

SOUZA, Maria T. S. de; OLIVERO, Simone M. Compras Públicas Sustentáveis: um estudo da incorporação de critérios socioambientais nas licitações do Governo do Estado de São Paulo. In: ENCONTRO DA ASSOCIAÇÃO NACIONAL DE PÓS-GRADUAÇÃO E PESQUISA EM ADMINISTRAÇÃO ENANPAD, 34., 2010, Rio de Janeiro. Anais... Rio de Janeiro: EnANPAD, 2010. p. 1-16.

SZANTO, Boris. Socio-technical functioning and anthropogenic crises. Systems Research and Behavioral Science, v. 15, n. 4, p. 297-313, jul./ago. 1998.

TRANSPARENCY INTERNATIONAL. Corruption perceptions index 2012. Disponível em: <www. transparency.org/cpi2012/results>. Acesso em: 15 out. 2014.

UNITED KINGDOM SUSTAINABLE PROCUREMENT TASK FORCE. Procuring the future. Disponível em: <www.defra.gov.uk/sustainable/government/documents/full-document.pdf> . Acesso em: 11 jan. 2011.

WCED. World Commission on Environment and Development. Our common future. Oxford: Oxford University Press, 1987.

Bernardo Carlos S. C. M. de Oliveira é bacharel e mestre em administração pela Universidade Estadual de Londrina (UEL), doutorando em ciências sociais pela Pontifícia Universidade Católica de São Paulo (PUC-SP). Membro do Núcleo de Estudos da Complexidade (Complexus). Doutorado Sanduíche na Columbia University — bolsa Capes/Fulbright 2014-15. E-mail: oliveira.bernardo@gmail.com.

Luis Miguel Luzio dos Santos é graduado em economia e em administração pela Universidade Estadual de Londrina (UEL-PR), doutor em ciências sociais pela Pontifícia Universidade Católica de São Paulo (PUCSP) e professor Adjunto do Departamento de Administração da UEL-PR. E-mail: lmig@uol.com.br. 